\title{
Prenatal maternal enrichment and restriction in rats: Effects on biological and foster offspring
}

\author{
MARGARET McKIM and WILLIAM R. THOMPSON \\ Queen's University, Kingston, Ontario, Canada
}

\begin{abstract}
Female rats were exposed during pregnancy either to enriched, restricted, or normal cage environments. At parturition, complete crossfostering of litters was carried out. Prenatal maternal treatment affected open-field scores both of biological and foster offspring. Largest effects were obtained for (a) offspring born of enriched mothers and reared by restricted mothers; and (b) offspring born of restricted mothers and reared by enriched mothers. Activity scores of the mothers themselves showed no effects of the pregnancy treatments.
\end{abstract}

It is now well established that various kinds of stresses imposed on pregnant females of different species can produce physiological and behavioral effects in the offspring (Archer \& Blackman, 1971; Joffe, 1969; Thompson \& Gruse, 1970). However, the kinds of treatments employed have usually been of a gross and drastic sort. Minimal interventions such as those used, for example, by Keeley (1962), and by Dennenberg and Rosenberg (1967 and Denenberg and Whimbey (1963) have been exceptional.

In the study described below, we have undertaken to examine the effects of simply exposing female rats to enriched, normal cage or restricted environments during pregnancy on the open-field activity of offspring. A complete crossfostering design permitted the estimation separately, and in interaction, of the effects of these treatments at the prenatal and postnatal stages of development. The effects of the treatments on maternal open-field activity were also measured.

\section{METHOD}

\begin{abstract}
Subjects
Subjects were 16 female Sprague-Dawley albino rats mated randomly to a common sample of 15 males at 80 days of age. Each of the resultant 16 litters of pups was culled to six, three females and three males, to yield a total of 96 offspring, later reduced to 95 due to the death of one animal. Pregnancy was determined by means of presence of vaginal plugs and by vaginal smear tests.
\end{abstract}

\section{Apparatus}

Three prenatal environments were used in the study as follows:

(a) Enriched environment. This consisted of a $120 \times 120 \times 30 \mathrm{~cm}$ enclosure with walls of clear plastic and roof and floor of $.625-\mathrm{cm}$ mesh. It contained seven "playthings" constructed of plywood and painted flat white. These objects were: a platform with ramp and stairs, a "teeter-totter," a right angle enclosed tunnel, a maze-like enclosed area with three entrances and two dividers, two dividers placed in a wedge shape, a solid block, and a solid cylinder. Since females assigned to this condition lived together, this environment may be considered to be enriched both perceptually and socially.

The work for this paper was supported by grants-in-aid from the National Research Council of Canada (APA-180), the Queen's University Research Committee and by a Canada Council Senior Fellowship to the second author.

Margaret McKim is now at Carleton University. (b) Restricted environment. This consisted of boxes $86.7 \times 60.62 \times 53.12 \mathrm{~cm}$ semisoundproofed by the use of styrofoam linings and divided into four chambers. In each chamber was placed a standard living cage $18.75 \times 17.5 \times 25.0 \mathrm{~cm}$. Two NE-51 neon bulbs were placed in the center of the dividers such that each cage received the same amount of diffuse light. Air was constantly circulated through the box by means of a fan and airvent. The fans also served to mask external noises. Only one female occupied the cage in each chamber.

(c) Control environment. This consisted of standard wire-mesh laboratory cages, $18.75 \times 17.5 \times 25.0 \mathrm{~cm}$ with one female housed per cage.

In all three environments, food and water were available at all times, and a 12-h light-dark schedule was maintained.

The open-field test consisted of a $90 \times 90 \times 60 \mathrm{~cm}$ plywood box with a white plastic floor marked off into $2517.5 \times 17.5 \mathrm{~cm}$ squares. A sound level meter registered a mean sound intensity level of $40 \mathrm{~dB}$ during testing, and the light-source generated $30 \mathrm{fc}$ at floor level.

\section{Procedure}

When pregnant, adult females were randomly assigned to one of the three treatment conditions. Two days before parturition, they were removed from their respective environments and housed in standard laboratory cages $22.5 \times 20.0 \times 43.75 \mathrm{~cm}$. Forty-eight hours after birth, whole litters from each biological mother were cross-fostered to a foster mother that had occupied a prenatal environmental condition different from or the same as that occupied by their biological mothers. Thus a nine-cell design was generated, representing all possible combinations of pre- and postnatal treatments. For the purpose of greater clarity, the final design is depicted in Table 1. Due to some gross disparities in

Table 1

Summary of Experimental Design Showing Number of Litters (L) and Number of Offspring (N) Tested in Each Treatment Condition*

\begin{tabular}{|c|c|c|c|c|c|c|c|}
\hline & & \multicolumn{6}{|c|}{$\begin{array}{l}\text { Prenatal Environment } \\
\text { of Foster Mother }\end{array}$} \\
\hline & & \multicolumn{2}{|c|}{$\begin{array}{c}\text { Enriched } \\
\text { (E) }\end{array}$} & \multicolumn{2}{|c|}{$\begin{array}{l}\text { Control } \\
(\mathrm{C})\end{array}$} & \multicolumn{2}{|c|}{$\begin{array}{l}\text { Restricted } \\
\text { (R) }\end{array}$} \\
\hline & & $\mathrm{L}$ & $\mathrm{N}$ & $\mathrm{L}$ & $\mathrm{N}$ & $\mathrm{L}$ & $\mathrm{N}$ \\
\hline $\begin{array}{l}\text { Prenatal } \\
\text { Environment } \\
\text { of Biological } \\
\text { Mother }\end{array}$ & $\begin{array}{l}\mathrm{E} \\
\mathrm{C} \\
\mathrm{R}\end{array}$ & $\begin{array}{l}2 \\
1 \\
2\end{array}$ & $\begin{array}{r}12 \\
6 \\
12\end{array}$ & $\begin{array}{l}1 \\
2 \\
2\end{array}$ & $\begin{array}{r}6 \\
12 \\
12\end{array}$ & $\begin{array}{l}2 \\
2 \\
2\end{array}$ & $\begin{array}{l}12 \\
12 \\
12\end{array}$ \\
\hline
\end{tabular}

${ }^{*}$ Note that no litter, even in the diagonal cells, was reared by its biological mother. 
dates of parturition between mothers and a number of resorptions and nonimpregnations, 16 litters constituted the final population (95 pups) with two litters for all except two treatment combinations.

Pups were weaned at 22 days of age, weighed, and moved from nesting cages to standard laboratory cages. Their mothers were also removed at the same time and housed in single living cages. On the same day and on Day 23, all pups and all mothers were tested for 2 consecutive days in the open-field test. Each subjects was placed in the center square of the apparatus, facing away from the experimenter. Ambulation scores (number of squares traversed) were counted separately for three 1-min trials on each of the 2 days of testing.

\section{RESULTS}

A mixed-model ANOVA for unequal Ns showed that offspring activity levels were influenced by environment of biological mothers $(\mathrm{F}=5.75, \mathrm{df}=2 / 86, \mathrm{p}<.005)$ and of foster mothers $(F=10.76, \mathrm{df}=2 / 86, \mathrm{p}<.001)$. A significant interaction between type of biological and foster mother $(F=4.83, \mathrm{df}=4 / 86, \mathrm{p}<.005)$ is shown in Figure 1. Thus, mothers exposed to an enriched environment during pregnancy produce more active offspring in general, this being most marked in pups fostered by a mother exposed to restriction during pregnancy; in general, pups born of restricted mothers showed lowest activity; but those fostered by enriched mothers were more active than any other group. Scores decreased across trials $(\mathrm{F}=12.63, \mathrm{df}=2 / 172, \mathrm{p}<.001)$ and to increase over days $(\mathrm{F}=29.82, \mathrm{df}=1 / 86$, $\mathrm{p}<.001)$. The decrease over trials was more pronounced on Day $2(F=6.97, \mathrm{df}=2 / 172, \mathrm{p}<.001)$. There were found to be no significant interactions between litter mean differences and any of the experimental variables.

Maternal activity scores declined over $(\mathrm{F}=30.32, \mathrm{df}=$ $2 / 26, \mathrm{p}<.001)$ and increased over days $(\mathrm{F}=15.73, \mathrm{df}=$ $1 / 13, \mathrm{p}<.001$ ) but were unaffected by environmental treatments.

\section{DISCUSSION}

The above data show clearly that variation in environmental complexity undergone by mother rats during pregnancy can produce definite changes in offspring behavior. The same prenatal variables must also influence postpartum behavior of mothers to their foster offspring. It seems likely that a variable level of intensity of maternal activity engendered by pregnancy treatment was responsible for changing offspring behavior, both pre- and postnatally.

These findings are of considerable importance since they show that quite minimal changes in the maternal environment can produce significant alterations in offspring behavior. It is significant, likewise, that if these same treatments have effects on the mothers themselves they are too transient to show up on the same test used to index changes in the young.

Of greater interest is the finding of an interaction between the pre- and postnatal variables. From it, we may educe that the actual nature of treatment-i.e., whether enrichment or restriction-may be of less importance than the contrast it makes with a

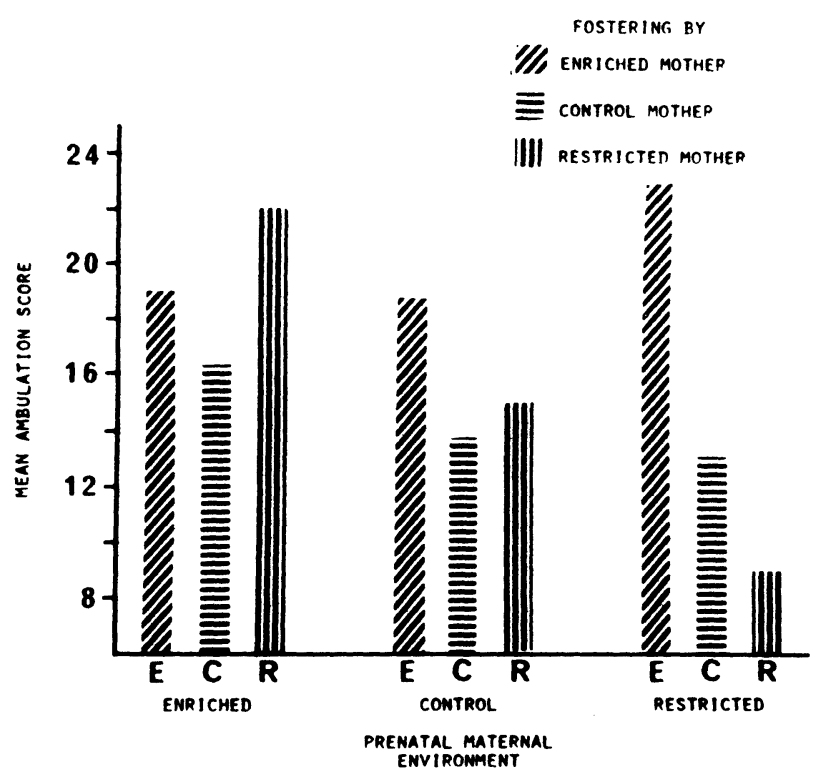

Fig. 1. Mean ambulation scores per minute of of fspring as a function of treatment of biological mother and foster mother during pregnancy.

treatment following or preceding it. Thus the highest activity levels were shown by offspring reared in the enrichment-restriction and restriction-enrichment conditions. These groups are also most different from the control-control group. Such a "contrast" effect appears to be fully in agreement with the suggestion put forward by Fuller and Clark (1966) that the effects produced in dogs by restricted early experience may be mainly due to the trauma of emerging from one kind of environment and entering another that is strikingly different. In the present study, the analogous contrast would lie in the transition from occupying a "quiet" uterine environment to rearing by an "active" mother and vice versa. Both types of sequence, however, produce an effect in the same direction-that is, a heightened activity level.

\section{REFERENCES}

Archer, J. E., \& Blackman, D. E. Prenatal Psychological Stress and Offspring Behavior in Rats and Mice. Developmental Psychobiology, 1971, 4, 193-248.

Denenberg, V. H. \& Rosenberg, K. M. Nongenetic transmission of information. Nature, 1967, 216, 549-550.

Denenberg, V. H., \& Whimbey, A. E. Behavior of adult rats is modified by the experiences their mothers had as infants. Science, 1963, 142,1192-1193.

Fuller, J. L., \& Clark, L. D. Genetic and treatment factors modifying the post-isolation syndrome in dogs. Journal of Comparative Physiology and Psychology, 1966,61, 251-257.

Joffe, J. M. Prenatal determinants of behaviour. International series of Monograms Experimental Psychology, Vol. 7, Oxford: Pergamon Press, 1969.

Keeley, K. Prenatal influence on behavior of offspring of crowded mice. Science, 1962, 135, 44-45.

Thompson, W. R., \& Grusec, Joan Studies of early experience. In Mussen, P. (Ed.), Carmichael's manual of child psychology. New York: Wiley, 1970.

(Received for publication November 25, 1974.) 